\title{
sciendo
}

\section{Effect of the French Contrast Method on Explosive Strength and Kinematic Parameters of the Triple Jump Among Female College Athletes}

\author{
by

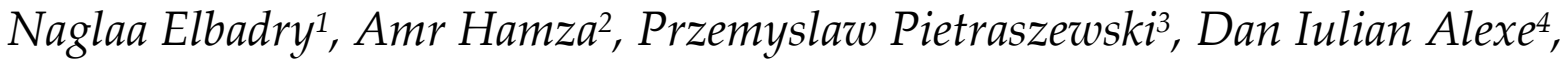 \\ Gabriel Lupu ${ }^{4}$
}

There are resistance training methods that result in strength, others that enhance hypertrophy and others that stimulate power. The training modality of contrast provides all of these benefits in one session. The concept of French Contrast training is based on a combination of complex and contrast methods. The idea is to use four exercises to induce physiological responses of the athlete and train along the force-speed curve. The primary purpose of the study was to investigate the impact of the French Contrast Method on explosive strength and kinematic parameters of the triple jump among female college athletes. Ten female college athletes from the Helwan University's track and field team participated in this study. Participants were assessed before and after an 8-week training program for upper and lower body explosive strength. No significant differences were observed in anthropometric characteristics. Explosive strength variables (Sargent jump test, countermovement jump, and seated medicine ball throw) increased significantly and kinematic parameters of the triple jump improved. The results indicated that eight weeks of the French Contrast training can improve both explosive strength and kinematic parameters of the triple jump.

Key words: French Contrast Method, explosive strength, kinematic parameters, triple jump.

\section{Introduction}

Biomechanics is the main field of objective research into the technical rules and methods of various kinetic skills. This is effected through precise measurements that are processed quantitatively by the laws of physics. There is no doubt that the objective study of any skill contributes to the development of the scientific foundations of the participant in terms of their ability to innovate and reach the best performance level possible.

The triple jump is an athletics field event, and is one of the most complex that requires specific abilities due to the difficulty inherent in the technical performance method which requires the jumper to repeat and exchange the fulcrum on both feet (hop, step, and jump). These fulcrums are the most difficult stages of performance because, during each fulcrum, the jumper changes the size and direction of both speed and force together and this requires explosive power employed according to mechanical laws (Abeer, 2014).

The triple jump is a combination of technique, form, and momentum combined with speed to produce explosive strength that is based on generating as much force as possible in the shortest time without losing efficiency. Explosiveness is trained by making quick movements with lighter loads. Plyometrics and ballistic training are the best examples of such

1 - Faculty of Physical Education for girls, Helwan University, Egypt.

2 - Faculty of Physical Education, Aswan University, Egypt.

3 - Institut of Sports Science. The Jerzy Kukuczka Academy of Physical Education in Katowice, Poland.

4 - Faculty of Movement, Sports and Health Sciences, Vasile Alecsandri University of Bacau, Romania. 
activities. However, there are more complicated types of training, such as the French Contrast Method, which may yield better results.

The French Contrast Method is an applied form of training derived from Post-activation potentiation (PAP) which is defined as an increase in muscle performance after a muscle contraction that could be a Maximum Voluntary Contraction (MVC), a tetanic contraction or a series of nerve impulses. Some types of stimuli can increase muscle contractions, the rate of force development (RFD) and explosive movements (Xenofondos et al., 2010). French Contrast training was originally developed by a French athletics coach, Gilles Cometti, but it was Dietz who took this method and molded it into a coherent whole for use by French athletics coaches. It is a combination of complex and contrast methods (Dietz et al., 2012). The idea is to use four exercises to induce physiological responses of the athlete and train along the force-speed curve. It is based on the concept of PAP (it establishes that a more powerful muscular contraction can be achieved if that contraction is preceded by a strong muscular contraction). It goes from a heavy compound lift, followed by a plyometric activity (complex training) (Joseba et al., 2018). Then, a powerful movement is carried out with a load of $30 \%$ (contrast training of the main compound) and, finally, it ends with an accelerated or assisted plyometric activity.

There has been considerable research into the functional significance of PAP for sports performance. This interest has revolved around the potential for enhancing the long-term training effect, typically in the forms of contrast training. According to Hilfiker et al. (2007), the preconditioning load used in the PAP intervention depends on the type of contractile activity used in the physical activity; however, this needs further research. To the best of our knowledge, most research has focused on biomechanical variables of the triple jump (Abeer, 2014; Allen et al., 2013; Allen, 2016; Liu and Yu, 2012; Milan and Otmar, 2011) or studied the effects of PAP in competitive sport (Gołaś et al., 2016), athletics disciplines such as the hammer throw (Karampatsos et al., 2013), sprints (Kümmel et al., 2016; Linder et al., 2010; Lim and Kong, 2013) or winter sports (Gołaś et al., 2017). There is no research connecting PAP and triple jump performance or analyzing the long- term effects of the French Contrast Method on kinematic parameters of triple jump performance.

Therefore, the primary purpose of this study was to investigate the impact of the French Contrast Method on explosive strength and kinematic parameters of the triple jump in female college athletes.

\section{Methods}

Experimental Approach to the Problem

One group (experimental) performed a pre- and post-training intervention which involved the assessment of explosive strength and kinematic parameters of the triple jump. Over an eight-week period, the experimental group trained for at least $50 \mathrm{~min}$ and a maximum of $70 \mathrm{~min}$ per day 3 times a week using the French Contrast Method. The training design is presented in Table 1.

Participants

Ten female college athletes from the Helwan University's team participated in this study. All participants were fully informed about the aims of the study and gave their voluntary consent before participation. The measurement procedures agreed with ethical human experimentation.

\section{Testing procedures \\ Physical tests}

Participants were assessed before and after an 8-week training program for upper and lower body explosive strength which included the following evaluations: Sargent Jump Test $(\mathrm{cm})$, countermovement jump $(\mathrm{cm})$, and seated medicine ball throw (meters). There was previous familiarization with accurate testing procedures. All the tests followed a general warm-up that consisted of running and stretching. The tests were performed with 3 trials and all the correspondent mean values were considered for statistical analysis. Rest periods between trials ranged from 10 to $20 \mathrm{~s}$.

\section{Instruments of kinetic analysis}

Given the importance of approaching as the direct preparation for the first support (Hop) and its success provide the best conditions for successful support, the last two steps of the approach stage will be considered.

The researchers employed dynamic analysis using two-dimensional (2D) video imaging as a means of collecting data. The kinetic analysis unit consisted of a laptop and kinetic 
analysis program (Winanalyze automatic motion analysis) which converted the footage of cadres that could be studied according to the kinetic treatment program. The researcher also used three cameras (Panasonic) working on a constant source of electricity and at one synchronized frequency of 60 cadres per second to photograph the technical stages and moments of time, and also the researcher used measure capacity $1: 25 \mathrm{~cm}$ and a set of adhesive labels to clarify the centers of the joints of the body.

The three cameras were set at a height of one meter so that the photography angle allowed the side of the jumper to be seen in full while in support, as the researcher's direction of photography and reflection of the sun and legal attempts and all the surrounding conditions. Figure 1 shows the positioning of the cameras.

\section{Statistical Analysis}

All statistical analyses were performed using the SPSS statistical package. The results are reported as means and standard deviations (SD).
The Paired Samples T-Test was used to compare the pre-tests and post-tests of the experimental group in terms of physical and biomechanical variables. The level of significance was set at $p \leq$ 0.05 .

\section{Results}

Table 2 shows anthropometric characteristics (age, body height and mass and training experience) of participants. No significant differences were observed in terms of anthropometric characteristics.

Table 3 shows a significant increase between pre- and post-tests in terms of explosive strength (Sargent Jump Test, countermovement jump, and seated medicine ball throw).

Table 4 shows a significant decrease between pre- and post-test results in all biomechanic variables, except the vertical velocity of the center of mass (Step) and triple jump distance (Hop). The improvement rate was between 0.22 and $16.74 \%$.

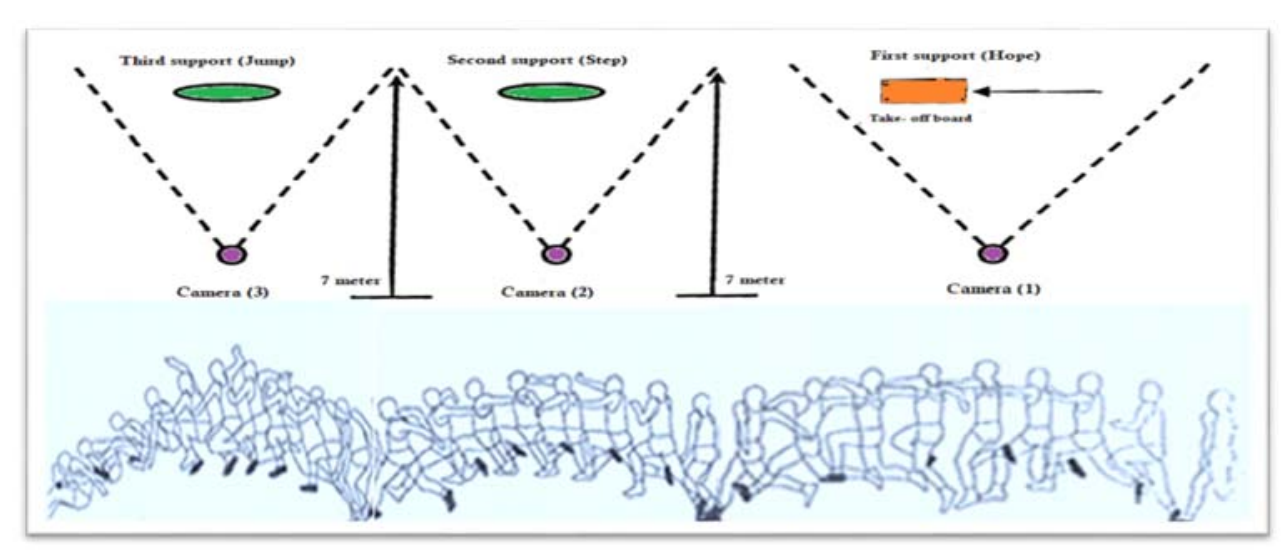

Figure 1

The positioning of the cameras

Table 1

Training program design

\begin{tabular}{|c|c|c|c|}
\hline Exercise & sets & Repetitions & Load \\
\hline Compound Exercise & \multirow{4}{*}{$3-4$} & $1-3$ & $80-90 \%$ \\
\hline Plyometric & & $3-5$ & Reactive \\
\hline Jump with free weight or weight jacket & & $3-5$ & $40 \%$ \\
\hline Acceleration Plyometrics & & 4-6 & Reactive \\
\hline
\end{tabular}

Reactive $=$ Movement executed as fast as possible.

No rest between exercises.

4-5 minutes of rest between sets. 


\section{Table 2}

Anthropometric characteristics of the subjects

\begin{tabular}{ccc}
\hline Variables & Mean & Skewness \\
\hline Age (years) & $20.6 \pm 1.34$ & 0.56 \\
Height $(\mathrm{cm})$ & $165.4 \pm 5.18$ & 0.77 \\
Weight $(\mathrm{kg})$ & $62.8 \pm 4.01$ & 0.82 \\
\hline
\end{tabular}

Table 3

Explosive strength Parameters

\begin{tabular}{|c|c|c|c|c|}
\hline \multirow[t]{3}{*}{ Kinematic parameters } & \multicolumn{2}{|c|}{ Experimental group } & \multirow[t]{3}{*}{ Rate of Change } & \multirow[t]{3}{*}{$\mathrm{P}$} \\
\hline & Before & After & & \\
\hline & Mean \pm SD & Mean \pm SD & & \\
\hline Sargent Jump Test & $68.29 \pm 0.12$ & $70.88 \pm 0.10$ & $3.79 \%$ & Sign \\
\hline Countermovement jump & $2.21 \pm 0.09$ & $2.25 \pm 0.10$ & $1.81 \%$ & Sign \\
\hline $\begin{array}{l}\text { Seated medicine ball } \\
\text { throw }\end{array}$ & $4.45 \pm 0.17$ & $4.55 \pm 0.28$ & $2.25 \%$ & Sign \\
\hline
\end{tabular}

\section{Table 4}

The kinematic Parameters

\begin{tabular}{|c|c|c|c|c|c|}
\hline \multirow[t]{3}{*}{ Kinematic parameters } & \multirow{3}{*}{ Phase } & \multicolumn{2}{|c|}{ Experimental group } & \multirow{3}{*}{$\begin{array}{l}\text { Rate of } \\
\text { Change }\end{array}$} & \multirow[t]{3}{*}{$\mathrm{P}$} \\
\hline & & Before & After & & \\
\hline & & Mean \pm SD & Mean \pm SD & & \\
\hline \multirow{3}{*}{$\begin{array}{l}\text { Horizontal velocity of the } \\
\text { Centre of mass (ms-1) }\end{array}$} & Hope & $8.29 \pm 0.12$ & $8.88 \pm 0.10$ & $7.12 \%$ & Sign \\
\hline & Step & $7.81 \pm 0.09$ & $8.00 \pm 0.09$ & $2.43 \%$ & Sign \\
\hline & Jump & $6.15 \pm 0.07$ & $6.55 \pm 0.08$ & $6.50 \%$ & Sign \\
\hline \multirow{3}{*}{$\begin{array}{l}\text { Vertical velocity of the } \\
\text { Centre of mass (ms-1) }\end{array}$} & Hope & $2.11 \pm 0.03$ & $2.35 \pm 0.05$ & $11.37 \%$ & Sign \\
\hline & Step & $2.32 \pm 0.45$ & $2.26 \pm 0.03$ & $2.59 \%$ & Not Sign \\
\hline & Jump & $2.15 \pm 0.15$ & $2.51 \pm 0.06$ & $16.74 \%$ & Sign \\
\hline \multirow{3}{*}{ Angle of take-off $\left(^{\circ}\right)$} & Hope & $12.70 \pm 0.15$ & $13.87 \pm 0.67$ & $9.21 \%$ & Sign \\
\hline & Step & $11.40 \pm 0.65$ & $12.80 \pm 0.69$ & $12.28 \%$ & Sign \\
\hline & Jump & $17.20 \pm 0.99$ & $19.85 \pm 1.21$ & $15.41 \%$ & Sign \\
\hline \multirow{3}{*}{ Height of central mass (m) } & Hope & $1.22 \pm 0.007$ & $1.31 \pm 0.008$ & $7.38 \%$ & Sign \\
\hline & Step & $1.14 \pm 0.02$ & $1.26 \pm 0.03$ & $10.53 \%$ & Sign \\
\hline & Jump & $1.24 \pm 0.02$ & $1.36 \pm 0.04$ & $9.68 \%$ & Sign \\
\hline \multirow{3}{*}{ Triple jump distance } & Hope & $4.64 \pm 0.24$ & $4.63 \pm 0.18$ & $0.22 \%$ & Not Sign \\
\hline & Step & $3.42 \pm 0.14$ & $3.67 \pm 0.15$ & $7.31 \%$ & Sign \\
\hline & Jump & $4.41 \pm 0.16$ & $4.58 \pm 0.12$ & $3.85 \%$ & Sign \\
\hline
\end{tabular}




\section{Discussion}

The goal of this study was to identify the impact of the French Contrast Method on explosive strength and kinematic parameters of the triple jump among female college athletes. The results indicated that eight weeks of French Contrast training can improve both explosive strength and kinematic parameters of the triple jump.

These changes are related to adaptations caused by French Contrast training. The unique combination of French Contrast exercises helps the central nervous system recruit a higher number of muscle fibers during athletic movements, which increases the rate of force development.

According to Strength \& Conditioning research, a higher rate of force development in lower body actions is correlated with greater jumping heights. The main mechanisms proposed as an explanation for this physical improvement are elastic energy utilization and the activation of the stretch reflex of the muscle (Bosco et al., 1982). In the downward phase, with rapid muscle elongation, elastic energy is stored in the musculotendinous component. If this elongation is immediately followed by a concentric action, the previously stored energy is released, enhancing the total amount of strength produced (Van and Zolotarjova, 2017). Especially when using plyometric training, it is possible to maintain high levels of stiffness in muscles, which results in better utilization of elastic energy. Confirmation of this can also be sought in the area of muscle electromyography (Stastny at al., 2017). The plyometric exercises included in the French Contrast program may improve performance through the stretch reflex, which is the involuntary response of the organism to an external stimulus that stretches the muscle. This may be the reason behind the greater effects observed after the implementation of the French Contrast program.

Horizontal velocity decreases during the jump phases, because of the three consecutive takeoffs. The change in velocity is $6 \%$ for the hop phase and more than twice that much during each of the succeeding phases (Hay and Miller, 1985). This means that the change in velocity ranges from 6.0 to $13.6 \%$. Miller and Hay (1986) reported values from 6.8 to $17.8 \%$ for relative changes in horizontal velocity during the jump phases. An increase in the changes of horizontal velocity would affect all three jump phases (Hop, Step, and Jump) according to Liu et al. (2015).

A reduction of horizontal velocity is a result of ensuring the optimal vector of vertical velocity. Vertical velocity is highest in the first phase (Hop) and the last phase (Jump). The lowest vertical velocity has been recorded in the step phase. Milan and Otmar (2011) indicated that the basic strategy of the tested subject was to preserve as high horizontal velocity as possible while ensuring optimal vertical velocity.

The method of contrast acts on the physiological and biomechanical factors on which the explosive force depends, being one of the most effective methods in terms of the activation of the fast motor units (Garhammer, 1993).

Our results are consistent with those of Tuura (2018), i.e. that the French Contrast training is highly effective at increasing vertical jump height. Through a mechanism called PAP, the heavy loading at the beginning of the circuit allows the athlete to jump to a greater height in all the subsequent jumps. Over time the following benefits of the French Contrast Method occur: strength gains, vertical jump improvement, and mobility enhancement, all in the same circuit.

\section{Practical Implications}

Sports that require high levels of force and power production in a limited amount of time, such as track and field jumps and throws, may benefit from the French Contrast Method due to its positive effects on performance, because this method is a valid, effective and less timeconsuming strategy to improve performance.

\section{References}

Abeer E. Biomechanical Evaluation of the Phases of the Triple Jump Take-Off in a Top Female Athlete. J Hum Kinet, 2014; 40(1): 29-35

Allen SJ, King MA, Yeadon MR. Trade-offs between horizontal and vertical velocities during triple jumping and the effect on phase distances. J Biomech, 2013; 46(5): 979-83 
Allen SJ, Yeadon MRF, King MA. The effect of increasing strength and approach velocity on triple jump performance. J Biomech, 2016; 49(16): 3796-3802

Bosco C, Viitasalo JT, Komi PV, Luhtanen P. Combined effect of elastic energy and myoelectrical potentiation during stretch-shortening cycle exercise. Acta Physiol, 1982; 114(4): 557-565

Čoh M, Kugovnik O. Variability of Biomechanical Parameters in the Triple Jump Technique - A Case Study. Sport Logia, 2011; 7(2): 113-121

Dietz C, Peterson B. Triphasic training: A systematic approach to elite speed and explosive strength performance. Bye Dietz Sport Enterprise; 2012

Garhammer J. A Review of Power Output Studies of Olympic and Powerlifting. J Strength Cond Res, 1993; 7(2): 76-89

Gołaś A, Maszczyk A, Zajac A, Mikołajec K, Stastny P. Optimizing post activation potentiation for explosive activities in competitive sports. J Hum Kinet, 2016; 52: 95-106

Gołaś A, Wilk M, Stastny P, Maszczyk A, Pajerska K, Zając A. Optimizing half squat post activation potentiation load in squat jump training for eliciting relative maximal power in ski jumpers. J Strength Cond Res, 2017; 31(11): 3010-3017

Hay JG. The biomechanics of the triple jump: a review. J Sports Sci, 1992; 10(4): 343-78

Hay JG, Miller JA. Techniques used in the triple jump. Int J Sports Biomech, 1985; 1: 185-196

Hilfiker R, Hubner K, Lorenz T, Marti B. Effects of drop jumps added to the warm-up of elite sport athletes with a high capacity for explosive force development. J Strength Cond Res, 2007; 21(2): 550-555

Karampatsos BG, Terzis G, Polychroniou C, Georgiadis G. Acute effects of jumping and sprinting on hammer throwing performance. J Phys Educ Sport, 2013; 13(1): 3-5

Kümmel J, Bergmann J, Prieske O, Kramer A, Granacher U, Gruber M. Effects of conditioning hops on drop jump and sprint performance: a randomized crossover pilot study in elite athletes. BMC Sports Sci Med Rehabil, 2016; 8(1): 2-8

Lim JJH, Kong PW. The application of post activation potentiation on sprint performance. J Australian Strength Cond, 2013; 21(1): 61-66

Linder EE, Prins JH, Murata NM, Derenne C, Morgan CF, Solomon JR. Effects of preload 4 repetition maximum on 100-m sprint times in collegiate women. J Strength Cond Res, 2010; 24(5): 1184-90

Liu H, Dewei M, Bing Y. Effect of Approach Run Velocity on the Optimal Performance of the Triple Jump. J Sport Health Sci, 2015; 4(4): 347- 52

Miller J, Hay JG. Kinematics of a World Record and Other World-Class Performances in the Triple Jump. Int J Sports Biomech, 1986; 2: 272-88

Niessen M, Jürgens A, Unger J, Burgardt K, Hartmann U. Time Management and Velocity Profiles in Elite Triple Jumping. In Proceedings of the 9th Annual Congress of the European College of Sport Science, Clermont-Ferrand, 2004; $3^{\text {rd }}-6^{\text {th }}$ July

Panoutsakopoulos V, Iraklis K. Essential Parameters in Female Triple Jump Technique. New Studies in Athletics, 2008; 23(4): 53-61

Stastny P, Gołaś A, Blazek D, Maszczyk A, Wilk M, Pietraszewski P, Petr M, Uhlir P, Zając A. A systematic review of surface electromyography analyses of the bench press movement task. PLoS One, 2017; 12(2): 1-16

Van Hooren B, Zolotarjova J. The Difference Between Countermovement and Squat Jump Performances: A Review of Underlying Mechanisms with Practical Applications. J Strength Cond Res, 2011; 31(7): 20

Xenofondos A, Laparidis K, Kyranoudis A, Galazoulas Ch, Bassa E, Kotzamanidis C. Post-Activation Potentiation: Factors Affecting It and The Effect on Performance. Journal of Physical Education and Sport, 2010; 28(3): $32-38$

\section{Corresponding author:}

\section{Przemysław Pietraszewski}

Institute of Sports Science. The Jerzy Kukuczka Academy of Physical Education in Katowice, Poland Mikolowska 72a str., 40-065 Katowice, Poland; E-mail: a.pietraszewski@awf.katowice.pl 